Daimon. Revista Internacional de Filosofía, no 84, 2021 pp. 183-197

ISSN: 1130-0507 (papel) y 1989-4651 (electrónico)

http://dx.doi.org/10.6018/daimon.459191

Licencia Creative Commons Reconocimiento-NoComercial-SinObraDerivada 3.0 España (texto legal). Se pueden copiar, usar, difundir, transmitir y exponer públicamente, siempre que: i) se cite la autoría y la fuente original de su publicación (revista, editorial y URL de la obra); ii) no se usen para fines comerciales; iii) se mencione la existencia y especificaciones de esta licencia de uso.

(c) (1) (3)

\title{
La autoridad de la primera persona como criterio de determinación y reconocimiento de la identidad de género
}

\author{
First-Person Authority as a Criterion for Gender Identity \\ Determination and Recognition
}

JORGE SUÁREZ MUÑOZ*

\begin{abstract}
Resumen: El interés principal de este artículo versa acerca de la posibilidad de justificar la autodeterminación como criterio fundamental para la determinación y el reconocimiento social de la identidad de género de un individuo. La reciente revisión de los criterios médicos abre el debate de su reemplazo por criterios de autopercepción y vivencia en primera persona. Por tanto, tomando como base la concepción de la autoridad como servicio de Joseph Raz y el fenómeno de la autoridad de la primera persona, se argumenta a favor de que los testimonios en primera persona son candidatos justificados para sustituir a los actuales criterios.

Palabras clave: autoridad, autodeterminación, sexo, género, reconocimiento, identidad.
\end{abstract}

\begin{abstract}
The focus of this paper is the possibility of justifying self-determination as the fundamental criterion for social determination and recognition of the individuals' sexual identity. The recent review of medical criteria has started a debate about their replacement by criteria based on self-perception and first-person experience. Therefore, taking as a basis Joseph Raz's service conception of authority and the first-person authority phenomenon, it will be argued that firstperson statements are justifiable substitutes for the current criteria.
\end{abstract}

Keywords: authority, self-determination, sex, gender, recognition, identity.

En el presente artículo se aborda la cuestión del reconocimiento de la identidad de género y los criterios que se emplean social, médica e institucionalmente para su determinación, además de la autodeterminación como principal alternativa que en los últimos años está siendo reivindicada como la sucesora de estos criterios instaurados hoy en una gran mayoría de sociedades. El objetivo principal consiste en analizar críticamente esta propuesta a fin de darle una justificación teórica y comprobar si constituye un mejor sistema de determinación de la identidad de género de los individuos.

Recibido: 08/12/2020. Aceptado: 27/02/2021.

* Estudiante de investigación doctoral del Departamento de Filosofía, área de Filosofía Moral y Política, de la Universidad de Málaga (suarezmjorge@uma.es). Líneas de investigación principales: filosofía moral y política, con especial atención a los fenómenos de autoridad epistémica y a los estudios sobre migraciones en el contexto europeo. 
Para ello, los dos primeros apartados hacen crítica al sistema de determinación actual. En el primero de ellos se expone la situación actual al respecto de la determinación del sexo a nivel legal e institucional, además de mostrar cuáles son los movimientos sociales que en las últimas décadas están promoviendo cambios. A continuación, en el segundo apartado, se aborda la cuestión de la determinación del sexo a nivel social, es decir, planteando cómo en la cotidianeidad de las relaciones sociales se suele reconocer la identidad de género de una persona. Esto va acompañado de una crítica de los criterios basados en la genitalidad de las personas para realizar esta determinación, así como una defensa de criterios basados en el testimonio en primera persona acerca de la identidad de uno mismo.

Tras esto, en el resto del artículo se ofrece una justificación para la alternativa de la autodeterminación. Así, en el tercer apartado se toma como punto de partida la concepción de la autoridad como servicio de Joseph Raz para dicha justificación, presentando sus tesis fundamentales y su relevancia en la explicación de la autoridad epistémica. En el último apartado, esta concepción de autoridad se conecta con el fenómeno de la autoridad en primera persona. Con todo ello se concluye que la autodeterminación puede ser justificada como un criterio de autoridad válido para determinar la identidad de género de una persona y consiguientemente reconocerle su identidad así expresada, constituyendo un sistema justificado y que resuelve problemas propios de los criterios tradicionales.

\section{Autodeterminación y reconocimiento legal en España}

La autodeterminación de género es una de las vindicaciones actuales más repetidas como medio para la completa promoción de los derechos de las personas transexuales ${ }^{1} \mathrm{e}$ intersexuales ${ }^{2}$ y, más en concreto, del derecho al libre desarrollo de la personalidad, tal y como viene recogido en el artículo 10.1 de la Constitución Española (Alventosa del Río 2016, 169-170).

El concepto de autodeterminación referido al género de la persona ha jugado un papel clave en las reclamaciones de diversas asociaciones y colectivos promotores de dichos derechos. Esto ha quedado reflejado en un creciente número de marcos legales actuales en que se hace mención explícita a la "soberanía [de] la voluntad humana sobre cualquier otra consideración física", citando la Ley Integral de Transexualidad de Andalucía ${ }^{3}$. O también el derecho al reconocimiento de la personalidad jurídica de la "identidad de género que cada persona defina para sî”, según lo expuesto en los Principios de Yogyakarta (ICJ 2007), uno

1 La terminología es variable y en los últimos años se están consolidando en diversos ámbitos los términos "transgénero", "trans" o "trans*". En el presente artículo, dado que se citan documentos legales, se empleará "transexual" o "transexualidad" para facilitar la homogeneidad terminológica. Entiéndase dentro de estos el resto de posibles acepciones que cubren los términos alternativos señalados.

2 En este artículo se pone el foco en las vivencias de las personas transexuales a fin de acotar el marco de estudio. No obstante, las personas intersexuales viven sus propias experiencias de violencia derivadas de la imposición del paradigma de la genitalidad sobre sus cuerpos desde el mismo momento de su nacimiento a través de cirugías no consentidas u otras prácticas que actualmente reciben grandes críticas por parte de colectivos sociales e instituciones internacionales. Para un análisis enfocado en la intersexualidad, véase García López (2015).

3 Ley 2/2014, de 8 de julio, integral para la no discriminación por motivos de identidad de género y reconocimiento de los derechos de las personas transexuales de Andalucía. 
de los documentos de referencia en derecho internacional en lo relativo a la interpretación de los Derechos Humanos en el colectivo LGBTI.

La autodeterminación del género surge en las últimas décadas como la propuesta político-social alternativa a la perspectiva médica y psiquiátrica que, desde la segunda mitad del siglo XX, se había instaurado como paradigma de acercamiento al fenómeno de la transexualidad. En 1977, la Organización Mundial de la Salud clasificó la transexualidad como síndrome médico. No fue sino hasta junio de 2018 que el mismo organismo la eliminó de la lista de patologías psiquiátricas, pasando a ser incluida en la lista de condiciones relativas a la sexualidad en la undécima publicación de la Clasificación Internacional de Enfermedades (CIE-11), bajo el título de "incongruencia de género" diversas consideraciones que ha tenido en las varias ediciones del Diagnostic and Statistical Manual of Mental Disorders (DSM) de la Asociación Estadounidense de Psiquiatría, acabando por desaparecer del listado de trastornos en su quinta edición, aprobado en $2012^{5}$.

Este proceso suele ser denominado como despatologización de la transexualidad. Como puede verse, hasta la década pasada no se ha culminado en la desaparición completa de los principales manuales médicos. Sin embargo, como en muchas otras ocasiones, las instituciones públicas no reflejan los cambios sociales en un marco legal hasta que dicho cambio se ha consolidado social y políticamente. Por ello, mientras que en muchos países siguen vigentes leyes aún fundamentadas en la visión de la transexualidad como un fenómeno perteneciente al ámbito médico, en otros, como la pionera Argentina, o en Malta y Noruega en el contexto europeo, ya se han realizado cambios para adaptar su legislación a la visión no medicalizada (ILGA World 2020; ILGA-Europe 2020). Además, en los últimos años, instituciones internacionales como la Comisión Europea promueven la adaptación de leyes basadas en la autodeterminación entre los estados miembros que aún no hayan realizado dicho cambio (Comisión Europea 2020).

En España, ciertamente se reconoce el fenómeno de la transexualidad, se permite el correspondiente cambio registral de nombre y de género y se protegen algunos derechos de las personas transexuales ${ }^{6}$. Ahora bien, todo el proceso de transición legal pasa por el sistema de salud, que debe certificar ciertos requisitos psiquiátricos y hormonales ante los tribunales y registros para validarlo. En España, la ley 3/20077 es la que regula que la petición de cambio registral debe incluir dos documentos médicos ${ }^{8}$ : un diagnóstico psicológico de disforia de género y un certificado de tratamiento médico durante al menos 2 años, sin requerir cirugía

4 El País, 19 de junio de 2018, «La OMS saca la transexualidad de la lista de enfermedades mentales». Accesible en: https:/elpais.com/internacional/2018/06/18/actualidad/1529346704_000097.html (consultado el 29 de diciembre de 2020).

5 El País, 5 de diciembre de 2012, «Los transexuales ya no son enfermos mentales». Accesible en: https://elpais. com/sociedad/2012/12/04/actualidad/1354628518_847308.html (consultado el 29 de diciembre de 2020).

6 Por ejemplo, se condenan ataques tránsfobos o se da derecho a los individuos a ser tratados acorde a su identidad de género y nombre sentidos en algunas instituciones públicas, aunque no en todas. No obstante, continúan sucediendo numerosos casos de, por ejemplo, exclusión institucional, imposición de intervenciones médicas o abusos policiales a personas transexuales e intersexuales (cf. FRA 2020).

7 Ley 3/2007, de 15 de marzo, reguladora de la rectificación registral de la mención relativa al sexo de las personas.

8 Cabe señalar que el artículo primero establece criterios formales de legitimación: nacionalidad española, mayoría de edad y capacidad suficiente. Estos criterios suponen la exclusión de base de personas no nacionales, menores o con diagnósticos psiquiátricos adicionales al de disforia de género. 
genital, solo hormonación. Conviene aclarar que este último requisito está exento solo en caso de riesgo para la salud de la persona paciente. Todo ello según el artículo 4 de dicha ley.

Así, existen dos reivindicaciones sociales convergentes. La primera, como señala la Comisión Internacional de Juristas (ICJ), que la despatologización de la transexualidad culmine en la prohibición de obligar a alguien a "someterse a procedimientos médicos, incluyendo la cirugía genital, la esterilización o la terapia hormonal, como requisito para el reconocimiento legal de su identidad de género" (ICJ 2007, 12). La segunda, que la autodeterminación reemplace a todo criterio médico como requisito para su reconocimiento social y legal.

De esta forma es como se han enunciado recientes propuestas como la Proposición de Ley contra la Discriminación por Orientación Sexual, Identidad o Expresión de Género y Características Sexuales, y de Igualdad Social de Lesbianas, Gais, Bisexuales, Transexuales, Transgénero e Intersexuales, presentada el 12 de mayo de 2017 en el Congreso de los Diputados. Dicha iniciativa legal propone la modificación del artículo 4 de la Ley 3/2007, eliminando los dos requisitos arriba mencionados y sugiriendo que:

La efectividad del derecho al reconocimiento de la identidad de género y, en su caso, la rectificación registral de la mención del sexo no vendrá supeditada a la existencia de un diagnóstico de disforia de género ni a la acreditación de haberse sometido a ninguna terapia o tratamiento médico o psicológico ni a ninguna intervención quirúrgica de reasignación, total o parcial9.

A pesar de que esta propuesta no fuese aprobada en su momento, resulta interesante remarcar lo que casi año y medio después se estableció desde la Dirección General de los Registros y el Notariado. En la Instrucción sobre cambio de nombre en el Registro Civil de personas transexuales ${ }^{10}$, tomándose como punto de partida que la aceptación de una ley a nivel estatal está retrasándose en su discusión y aprobación, se afirma que "mientras eso llega, hay situaciones actuales que demandan una solución urgente”.

La Instrucción establece la posibilidad de presentar una solicitud de cambio de nombre - no de sexo- que será tramitada para adecuarlo a la identidad de género sentida por la persona, aunque sea discrepante con el sexo registrado. La justificación dada se basa en la vigente Ley de Registro Civil de 1957, que obliga a que el nombre registrado no induzca a confusión del sexo de la persona. La novedad, no obstante, radica en entender que el sexo de la persona denomina a la identidad sentida y no al sexo registrado, como podemos leer en la instrucción referida:

Debe analizarse cuál es el verdadero sexo correspondiente a las personas con disonancia de género, si el que viene dado por sus órganos genitales, que determinó que al nacer se le inscribiera como perteneciente al mismo, o el verdadera y profundamente sentido por dichas personas, y parece que la respuesta debería ser que este

9 Proposición de Ley 122/000097, publicada en el Boletín Oficial de las Cortes Generales (BOCG) el 12 de mayo de 2017, núm. 122-1.

10 Instrucción de 23 de octubre de 2018, de la Dirección General de los Registros y del Notariado, sobre cambio de nombre en el Registro Civil de personas transexuales. 
último, dada la apuntada prevalencia de los factores psicosociales. De este modo, no se produciría una absoluta contradicción con la exigencia del art. 54, de impedir el error en cuanto al sexo ${ }^{11}$.

Se ve, por consiguiente, el intento de adaptación del marco legal al proceso de despatologización señalado, otorgando prioridad al testimonio directo del sujeto, sin necesidad de que medie el personal sanitario o se establezcan otros criterios más allá de la autopercepción del sujeto. Por supuesto, la tramitación de la llamada "Ley Trans", que se está llevando a cabo en la actualidad, está completamente alineada con la idea de dotar de fuerza legal a la autodeterminación de género como criterio.

Esto puede ser conceptualizado como un cambio en la forma de determinación de la identidad de género que de forma general se emplea social e institucionalmente. Para esclarecer este aspecto, en el siguiente apartado se aborda el modo en que de forma cotidiana las personas reconocen la identidad de otras, además de las instituciones. En primer lugar, desde un punto de vista descriptivo, para luego poder afrontar una crítica del sistema así descrito.

\section{La determinación del sexo: la genitalidad como criterio}

Como se señalaba al final del apartado anterior, la observación de los genitales externos en el momento del nacimiento constituye el modo automático de registro del sexo de un neonato. A lo largo de la vida del individuo, su identidad de género tiene una presencia muy importante, tanto en la percepción de sí mismo como en la percepción que otras personas tienen de él.

Esta asignación de acuerdo con la genitalidad, que se realiza de forma tan natural en la mayoría de las sociedades, ha sido señalada por Talia Mae Bettcher como el paradigma de determinación social del sexo. De hecho, esta va más allá del momento del nacimiento, alcanzando virtualmente todos los momentos de la vida de un individuo. A juicio de la autora, la presentación del género de una persona va ligada irremediablemente a una presentación de su genitalidad, que juega un papel fundamental a la hora de determinar el sexo biológico, incluso cuando no es compartido por otras características como pudiera ser el cariotipo (Bettcher 2009, 106).

Siguiendo este modelo, frente a la declaración de una persona del tipo "soy un hombre" o "soy una mujer", se estaría interpretando que posee, respectivamente, pene o vagina, ya que eso fue lo que en el momento de su nacimiento marcó su registro de sexo. Ahora bien, no parece que, cuando preguntamos por el género de alguien, estemos interesándonos por su estatus genital. En este sentido, está completamente fuera de lugar que, tras la declaración de la identidad de género de una persona, se le exija cualquier tipo de verificación de sus genitales. Más aún, cualquier intento de realizar tal acción supone una violación clara del derecho a la intimidad de la persona.

Desde una perspectiva descriptiva, el criterio de determinación del sexo de un bebé estaría basado en su genitalidad visible, y este criterio se perpetuaría de forma incuestionada aun cuando pierda su componente de constatación empírica. Como se aclara más abajo,

11 Ib. 
esta perspectiva estaría estableciendo una relación causal donde solo hay una correlación de hechos. Aún más, desde una perspectiva crítica, cabe plantearse qué nivel de validez puede llegar a tener este criterio de determinación, considerando que es o bien incompatible con el derecho a la intimidad en caso de que debiera ser constatado, o bien no constatable empíricamente, en caso de que no se exija la revelación genital.

Esto es, precisamente, lo que Bettcher señala como una de las formas de discriminación más extendidas al concebir a las personas transexuales como "farsantes" (pretenders) o "impostores" (deceivers). Por ejemplo, cuando a una mujer transexual se le cuestiona y esta declara públicamente su anatomía genital, a menudo puede recibir declaraciones como: "en realidad es un hombre" (Bettcher 2014: 391). Esto esconde un sistema de verdad, en el que el criterio de verificación de la identidad de género de una persona es su estatus genital. De este modo, las personas cisexuales ${ }^{12}$ serían quienes cuentan con la correspondencia correcta entre identidad de género y genitales, mientras que las personas transexuales se ubicarían en una correspondencia errónea o desviada. De ahí que se empleen formas adverbiales como "en realidad", "realmente" o "verdaderamente" en declaraciones similares a la escrita anteriormente.

Otro ejemplo muy ilustrativo es expuesto por Julia Serano en referencia a la caracterización de personajes transexuales en medios como el cine. La autora señala que en conocidas películas y series existe un arquetipo de personaje, que es secretamente transexual, y que acaba teniendo un momento de "revelación de la verdad" en la trama. Tras este momento de revelación, su identidad sentida queda anulada por el descubrimiento de su anatomía física, que acaba imponiéndose como su supuesta identidad real (Serano 2007, 37).

Por último, a esto se puede añadir las cifras de homicidios violentos de personas transexuales. Según apuntan Kristen Schilt y Laurel Westbrook, solo el 33 por ciento de estos homicidios tenían una causa no relacionada con la condición de transexualidad de la víctima. A su vez, hasta el 56 por ciento del total resultó de interacciones sexuales íntimas en que el agresor se sintió de algún modo "engañado para realizar prácticas homosexuales" y un 6 por ciento por otros tipos de homofobia y transfobia (Schilt y Westbrook 2009, 452). El elevado número de agresores que alegó sentirse conducido a prácticas homosexuales ${ }^{13}$ refuerza la idea de que la identidad de género de la víctima es revelada acorde a sus genitales, imponiéndose a su propia identidad sentida.

Por tanto, la vindicación directa que surge tras haber señalado esta conexión es la necesidad de poner en crítica el papel de la genitalidad de una persona en el reconocimiento social del género. Legitimar un mecanismo social en que los genitales puedan ser un criterio para establecer la identidad de género, más allá de la etapa como bebé, es difícilmente conciliable con el respeto al derecho de la intimidad de las personas. No obstante, la suficiencia de la autodeterminación como criterio ha estado enfrentada con críticas por parte de un número importante de filósofos.

12 El término "cisexual" o "cissexual" fue introducido como antónimo de "transexual". Se refiere a personas cuyo sexo sentido se corresponde con el sexo registrado al nacer. Al igual que ocurre con "transexual", podemos encontrar las variantes "cis" o "cisgénero".

13 En varios países, y especialmente en Estados Unidos, este tipo de defensa ha sido empleada exitosamente para rebajar la dureza de las sentencias. Esta estrategia de defensa se ha nombrado trans panic, por analogía y similitud con la defensa gay panic. Un estudio más detallado sobre el tema puede encontrarse en Wodda y Panfil (2015). 
Entre otros, Pablo de Lora ha expuesto recientemente bastantes reservas a la hora de aceptar el cambio de paradigma hacia la autodeterminación. Para él, el tratamiento social y la creencia personal pueden diferir en lo relativo a la identidad de género de otra persona:

Tengo para mí que de un modo análogo [a como reconocemos como hijos naturales a los adoptivos] deberíamos interactuar con quienes se reclaman hombres o mujeres por mera voluntad, aunque en nuestro fuero interno creamos que no es tal identificación sino lo que la naturaleza haya brindado lo que finalmente tenga que contar (De Lora 2019, 193).

De este modo, aunque se acepte la identidad autopercibida en el trato cortés cotidiano con esa persona, podría objetarse, como hace Pablo de Lora, que esto debiese alcanzar la esfera de nuestras categorías y el modo en que entendemos el mundo. Existiría, por tanto, una distinción entre el plano ético del tratamiento y el plano epistémico del reconocimiento.

Evidentemente, existen razones de peso para tratar a una persona acorde con su identidad declarada. Actuar de forma contraria en un contexto cotidiano a menudo será reprochado como innecesaria e injustamente violento e irrespetuoso. Pero actuar de un modo determinado por razones de convivencia y respeto no necesariamente va ligado a una creencia al respecto de algo. La libertad religiosa podría ofrecer un símil ilustrativo. Alguien podría pensar que ciertos dogmas de algunas religiones son absurdos e incluso guarde para sí la consideración de que son creencias irracionales. Ahora bien, ante una persona que se declare profundamente creyente en un contexto cotidiano, acusarla de irracional o absurda sería algo reprochable de acuerdo con valores de convivencia y respeto que deberían primar.

De este modo, la determinación del género de los individuos humanos en el plano epistémico-ontológico es independiente y queda desconectado de las exigencias morales que se hagan en el trato cotidiano a personas transexuales. En la esfera de las creencias y el conocimiento, para Pablo de Lora, la genitalidad heredada de la persona tendría primacía sobre la autopercepción del individuo. La posición de este filósofo, que expone a lo largo de su obra, estaría indicando que la determinación del género sucede de acuerdo con características biológicas y es concluyente, es decir, que no puede ser modificada a lo largo de la vida del individuo. Para él, el dimorfismo sexual "es un hecho biológico, no una construcción cultural ni una realidad institucional, pues no depende de nuestros estados mentales, sino de cómo es la naturaleza" (De Lora 2019, 178). Esta tesis sería la opuesta a la de Judith Butler, para quien un cuerpo u otro no es determinante en la construcción de la identidad de mujer u hombre (Butler 1986, 35; 1990, 6).

Mientras que, a juicio de Pablo de Lora, el dimorfismo sexual constituye diferencias esenciales entre hombres y mujeres, para Judith Butler son características meramente accidentales y no conectadas de forma necesaria con la identidad de género de cada cual. Siguiendo la idea de Butler, entre la genitalidad de las personas y su identidad de género solo se puede establecer una correlación no causal, meramente probabilística. Así, el hecho de que al neonato se le registre un sexo u otro según la observación de sus genitales solo se basa en probabilidades de acierto: la mayoría de los hombres tienen pene y la mayoría de las mujeres tienen vagina. No obstante, de ningún modo, siguiendo a Butler, podríamos decir 
que existe una relación causal entre genitalidad e identidad de género, sino que el cuerpo de cada persona sirve como ocasión de construcción de una identidad de género que en todo momento puede ser de distintas formas (Butler 1986, 46; 1990, 111-112).

Ahora bien, se puede ver que la tesis de Pablo de Lora contraviene a lo expuesto anteriormente acerca de la forma normal en que se suele descubrir la identidad de género de una persona. Esto es, preguntándole. Pongamos el caso de que alguien dice identificarse como mujer. Sin embargo, juzgando su apariencia física y basándose en creencias personales, uno considera que esa persona "es un hombre por naturaleza", siguiendo la tesis de Pablo de Lora. Por supuesto, en todo momento sería posible hacer cavilaciones internas e, incluso, el más imprudente podrá lanzarse a preguntarle directamente, aun siendo esta una pregunta de lo más íntima ${ }^{14}$. Ahora bien, si la persona preguntada se acoge a su derecho de no hacer público su estatus genital u otras condiciones anatómicas, genéticas o biográficas, como generalmente se consideraría que debería suceder, ¿no resulta que uno debería acogerse al testimonio de la propia persona y desistir de su indagación al respecto? De este modo, dado que el estatus anatómico y genético de la persona es de ámbito privado, la identidad sentida y declarada parece una apuesta mucho más accesible y segura para cerrar la deliberación sobre la identidad de género de esta.

De hecho, se entiende que el estatus genital de una persona solo se debería revelar en el ámbito íntimo de la persona o por motivos médicos relevantes. Por consiguiente, dado que la identidad de género de una persona afecta fundamentalmente a su vida en el trato social e institucional que reciba día a día, resulta coherente reducir la relevancia de la condición corporal de la persona a su ámbito privado y priorizar la identidad que expresa públicamente en el resto de su vida.

Por ello, la autoridad de la primera persona ${ }^{15}$ se puede plantear como una característica privilegiada para establecerse como una vía alternativa para el reconocimiento de la identidad de género de una persona. La autoridad de la primera persona permite analizar el acceso asimétrico que los agentes tienen a los contenidos mentales propios respecto de los ajenos. En línea con las ideas expuestas en párrafos anteriores, la identidad de género de una persona sería accesible, si no de forma exclusiva por ella misma, al menos sí de forma mucho más inmediata y eficaz.

Sin embargo, antes de seguir profundizando en este ámbito, resultará útil establecer una base sobre la que poder explicar y justificar el fenómeno de la autoridad en un sentido más amplio. De este modo, tras un análisis más detallado acerca de qué supone tener o ser una autoridad sobre algo, se podrá entender mejor de qué forma puede establecerse la autodeterminación del género como un criterio más adecuado que el estatus genital.

14 Son muchas las personas que señalan esto como una de las discriminaciones más normalizadas y extendidas que sufren las personas transexuales, puesto que es una pregunta que típicamente reciben estas por el hecho de ser transexuales, y que les pone en una situación social delicada y de presión. Ozturk lo conceptualiza como una violación de la intimidad prohibitiva (Ozturk 2017, 147).

15 Este término proviene del inglés "first-person authority", y debe entenderse como un privilegio de acceso epistémico en la relación entre el sujeto y sus propios estados mentales. No debe confundirse con que la autoridad de la primera persona solo se aplica a la propia persona y no al resto de agentes (Cf. Davidson 1984, 101-102). 


\section{Razones y autoridad}

Para introducir la argumentación sobre autoridad y creencias, merece la pena tomar como punto de partida el célebre capítulo 10 de la Investigación sobre el entendimiento humano. David Hume afirmó en él que el modo normal en que un sujeto conforma sus creencias consiste, resumidamente, en un balance de todas las razones pertinentes al respecto de algo, optando por la interpretación que parece más sólida:

Un hombre sabio [...] sopesa las experiencias contrarias, considera qué posibilidad es la apoyada por el mayor número de experiencias, se inclina por esta posibilidad con dudas y vacilaciones, y cuando, finalmente, ha fijado su juicio, la evidencia no excede a lo que, hablando con propiedad, llamamos probabilidad. Toda probabilidad, por tanto, supone una oposición de experiencias y observaciones, encontrándose que una posibilidad aventaja a las otras (Hume 1988, 135).

En la terminología epistemológica actual, es posible entrever en Hume lo que hoy se denominan "razones para creer" (reasons for belief). Algunas de las experiencias de las que el filósofo habla no necesariamente son observaciones directas o sensaciones percibidas en primera persona, sino también testimonios o información aportada por otros sujetos creíbles. Las razones para creer serían, por tanto, hechos ${ }^{16}$ que hablan en favor de sostener una cierta creencia como verdadera.

De forma normal, es posible apuntar que los agentes puedan tener creencias muy dispares al respecto de un mismo fenómeno o cosa. También pueden discrepar en que, ante una circunstancia en la que se deba tomar una decisión, la acción adecuada puede ser una u otra. Por supuesto, los agentes sostienen una posición u otra porque es la que consideran correcta. Algunos autores, como Linda Zagzebski, explican esto como el "deseo natural por la verdad" (Zagzebski 2012,33), mientras que otros aluden a argumentos pragmatistas para justificar esta posición basándose en la consecución de fines loables (Williams 2002). Pero aun ofreciendo explicaciones diferentes, lo más importante es destacar que los agentes ofrecerán razones para creer cuando deban rendir cuentas de por qué creen lo que creen. De este modo, tanto nuestras decisiones como nuestras creencias descansan sobre aquellos hechos que podemos aportar como explicación y justificación. El tipo de razones de interés para el presente artículo son las razones de autoridad. Estas se pueden identificar como aquellas que se defienden de forma espontánea mediante la afirmación "es una razón correcta porque lo ha dicho A", siendo A un agente con autoridad en el asunto implicado.

En el campo de la autoridad, la concepción desarrollada por Joseph Raz es de interés para establecer la base teórica de la autoridad epistémica. La concepción de la autoridad como servicio de Raz constituye una explicación del fenómeno de la autoridad de notable influencia en la actualidad. Raz parte de un proyecto de análisis de otras explicaciones de la autoridad, como la crítica frontal al anarquismo de Wolff o la revisión a la concepción de

16 Podría ser discutido si las razones son solo hechos o estas incluyen ciertos estados psicológicos e intencionales. A efectos de limitar la extensión, en este artículo tomo como base la idea de que las razones son hechos objetivos del mundo y, por tanto, pueden ser reconocidas y compartidas por todos los agentes (Cf. Raz 1975, 17). 
autoridad de Hart. A partir de ahí, este filósofo propone que la forma normal de justificar la autoridad se basa en que supone una forma de acertar mejor respecto a qué debería ser llevado a cabo. Según afirma, la autoridad satisface dos tesis: dependencia y justificación normal. De este modo, en The Morality of Freedom, señala que cualquier mandato de autoridad se refiere a razones que se aplican al caso con anterioridad al propio mandato (dependencia) y es más eficaz para alcanzar una deliberación correcta que la que podría alcanzar de forma independiente el sujeto que lo recibe (justificación normal) (Raz 1986, 42-57).

Para que se aprecie adecuadamente la relevancia de esta concepción para el propósito de este artículo, resulta necesario concretar mejor lo que resulta de interés de estas dos tesis. En primer lugar, cuando una autoridad articula un mandato, debe ser esperable que las razones a las que alude ya eran aplicables a la acción que prescribe con anterioridad. Dicho de otra forma, la autoridad debe emplear y señalar razones que ya eran pertinentes, pero que quizás no estaban siendo consideradas de la forma adecuada a la hora de tomar una decisión. En esto consiste la tesis de la dependencia. De este modo, una autoridad no puede legítimamente realizar mandatos caprichosos o injustificados, sino que tiene que atender a las circunstancias y variables que afectan a la deliberación ( $\operatorname{Raz} 1986,47)$.

Por otra parte, los mandatos de autoridad no son meras declaraciones lanzadas al aire, sino que aspiran a ser obedecidos por sus receptores. Esto implica que debe existir una justificación para tal obediencia. A juicio de Raz, ello se condensaría en la tesis de justificación normal, según la cual la obediencia a un mandato de autoridad se justifica por ser una mejor estrategia para actuar del mejor modo (Raz 1986, 53).

Una figura de autoridad se ubicaría, por tanto, en una posición más adecuada que quien obedece para deliberar y sopesar las razones que se aplican al caso. De este modo, la concepción de la autoridad como servicio señala la importancia de entender que la naturaleza de este fenómeno es servir para acertar más eficazmente en las acciones que se realizan. En otras palabras, una autoridad es merecedora de ser obedecida por su efectividad a la hora de prescribir lo que es más acertado. Por lo tanto, la posibilidad de la desobediencia puede verse como una estrategia ineficaz.

Aunque la concepción de Raz esté descrita en casi toda su obra como una explicación de la autoridad en sentido práctico, aplicada al ámbito de las acciones, resulta útil su traslación al ámbito de las creencias. Por ejemplo, parece lógico pensar que una persona experta en nutrición será tomada como una autoridad sobre, entre otras cosas, el impacto esperable de la ingesta de un determinado alimento sobre el cuerpo de quien lo consuma. Si esta persona afirma que el consumo frecuente de dicho alimento puede provocar trastornos en el metabolismo, sería prudente creerle, incluso aunque para uno sean desconocidas todas las investigaciones realizadas o no tenga conocimiento científico alguno. Esto parece satisfacer las dos tesis de Raz señaladas anteriormente. En primer lugar, las razones empleadas por la persona experta serán hechos empíricos que podrían ser verificados por cualquiera, y no consideraciones u opiniones personales - tesis de dependencia-. En segundo lugar, su afirmación actúa con autoridad ya que es una forma más eficaz de obtener conocimiento verdadero que intentar deducirlo por uno mismo - justificación normal - (Zagzebski 2012, 109-110).

Una vez se ha desarrollado la concepción de la autoridad como servicio y la posibilidad de extenderla al ámbito de las creencias, esto debe ser ahora contrastado con la determinación de la identidad de género. Si la autoridad de la primera persona demuestra ser una forma eficaz 
de determinarla, entonces la concepción de la autoridad como servicio constituiría una posibilidad de justificación apropiada para defender la autodeterminación como criterio fundamental.

\section{La autoridad de la primera persona en la identidad de género}

La autoridad de la primera persona ha sido conceptualizada de diversas formas, de entre las que se pueden destacar tres: epistémica, ética y negociativa. La concepción epistémica se basa en el tipo de relación que se establece entre un sujeto y sus propios estados mentales, frente a la relación de terceras personas con estos. En la valoración de la afirmación de una persona del tipo "la casa está en llamas", Donald Davidson señala que existen al menos tres aspectos a evaluar: si la casa está en llamas, si el hablante tiene la creencia de que la casa está en llamas y el modo en que el fuego ha causado su creencia (Davidson 1984). La autoridad de la primera persona se hace manifiesta en el segundo de los aspectos, que se justifica en breve más abajo.

En segundo lugar, la concepción ética pone en valor las profundas dudas que se puede tener al considerar la frecuencia con la que se producen autoengaños, sesgos o negaciones inconscientes. Ante esto, la posición ética de la autoridad de la primera persona resta relevancia al factor epistémico del acceso privilegiado, para asentar la justificación sobre la responsabilidad individual de quien expresa estados psicológicos propios. De acuerdo con Krista Lawlor, la autoridad de uno sobre sus propias emociones y estados no descansa sobre si tiene razón o no, sino sobre su responsabilidad sobre ellos (Lawlor 2010, 550). De este modo, cuando alguien comunica que tiene o no un deseo de hacer algo, la respuesta del resto de personas debería ser acorde con ello. Por consiguiente, una persona no puede asumir el papel de asignar a otra sus propios estados mentales. Por más que pueda preguntarle acerca de ellos, la última decisión de establecer cuáles son y rendir cuentas de ellos recae siempre sobre la primera persona (Bettcher 2009, 101-103).

Sin embargo, la concepción ética implica una obligación por parte de terceras personas de no rechazar las afirmaciones desde la autoridad de la primera persona que, para algunos filósofos, resulta injustificadamente tajante (Ozturk 2017, 140). Por ello, la teoría negociativa se plantea como una versión más flexible que la anterior, además de más ajustada al ámbito de las identidades personales. Según Burkay Ozturk, quien formula y da nombre a esta concepción de la autoridad de la primera persona, existen conceptos identitarios que se definen de forma comunitaria, no individual, tales como la nacionalidad, la religión o la propia identidad de género. Así, para Ozturk, la adscripción de una identidad comienza desde la primera persona, pero no concluye aquí. La identificación de alguien podría aún ser puesta en duda por terceras personas, siempre que esta duda no viole tres límites éticos: no dañar, no invadir la privacidad y respetar la dignidad (Ozturk 2017, 145-150).

No obstante, Davidson señaló un aspecto de la concepción epistémica de la autoridad de la primera persona que bien puede conectar con las otras dos concepciones. También permite conectar con la concepción de la autoridad como servicio, como se expone más adelante. Este aspecto se basa en que la interpretación del mensaje por parte del receptor está necesariamente mediada por esquemas mentales propios y asunciones. Por el contrario, para el emisor, que quiere ser entendido, no procede la duda acerca de si realmente quería decir lo que dice (Davidson 1984, 110). Por supuesto, el emisor siempre puede equivocarse 
en el significado las palabras escogidas, pero esto no elimina la asimetría de la adscripción de estados mentales entre el emisor y el receptor.

De este modo, las tres perspectivas de la autoridad de la primera persona, aun difiriendo en diversos puntos, se mostrarían de acuerdo en que existen razones para justificar la asimetría entre la relación de los estados psicológicos con uno mismo y con otros. A partir de esto, difieren al respecto de si esta asimetría debe entenderse en términos éticos, sociolingüísticos o epistémicos (Gertler 2020). Para poder conectar adecuadamente con la concepción de la autoridad como servicio de Raz, la perspectiva de Davidson definida en el párrafo anterior puede resultar suficiente y apropiada para mostrar cómo la autoridad de la primera persona puede justificarse.

Joseph Raz ya señala que, a pesar de que su teoría esté desarrollada teniendo en el foco a la autoridad en sentido práctico, el fenómeno de la autoridad en el ámbito epistémico debe tener la misma estructura básica (Raz 1986, 53). En definitiva, lo definitorio de la autoridad como fenómeno es que funciona en el ámbito de las razones, por tanto, en el campo deóntico. Aunque la autoridad práctica y la epistémica difieran en sus contenidos, su justificación es común y radica en el qué debe uno hacer o creer (Raz 1986, 30). Por consiguiente, si se acepta que las autoridades epistémicas tienen plena cabida en la concepción de la autoridad como servicio, la justificación de la autoridad de la primera persona debería satisfacer las dos tesis de justificación que fueron expuestas más arriba.

En cuanto a la tesis de la dependencia, la autoridad de la primera persona debería funcionar siempre señalando razones para creer algo que ya existía. Cuando la comunidad científica ha estado defendiendo el cambio climático, siempre ha hecho uso de diversas observaciones, mediciones y hechos que son relevantes y ya existían. Aunque uno no sepa los métodos por los que se puede calcular el incremento de la temperatura media global, no significa que tal incremento no sea real, y la comunidad científica se limita a señalarlo como una razón a favor del cambio climático.

Del mismo modo, ante la afirmación de una persona del tipo "soy un hombre", las razones que se pueden ofrecer para sostener esa afirmación deberían satisfacer esta tesis. Estas razones pueden variar según la concepción de la conformación del sexo que se suscriba. Como se ha señalado, para algunos autores es una cuestión anatómica. Para otros, es una identidad construida a partir de vivencias internas o comportamientos sociales (Cf. Mikkola 2019). Ahora bien, como señala Ozturk, la identidad de género a menudo es presentada como multifactorial y las razones pertinentes para defenderla son variables. Sin embargo, la pertinencia de estas para poder ser sostenidas como buenas razones radica en gran medida en que pueda ofrecerse una justificación razonable (Ozturk 2017, 150-151).

Tómese un caso hipotético a menudo planteado por los críticos de la autodeterminación: un hombre que, con la finalidad de beneficiarse de medidas de acción positiva para la igualdad entre mujeres y hombres, decide presentar una petición de cambio de sexo para ser considerado como mujer. ¿Qué razones son esperables que aporte al afirmar que "es una mujer"? Más allá de las razones anatómicas que algunos podrían señalar, la vivencia experiencial que este sujeto pueda tener como "ser mujer" diferirá radicalmente de la que una mujer transexual normalmente tiene.

De este modo, "sentirse mujer" sería una razón que se adapta a la tesis de dependencia solo en el caso de la mujer transexual, pues es un hecho que esta mujer tenía bien formado y 
con anterioridad a su declaración de identidad de género (Cf. Bettcher 2014). Esto mismo, por supuesto, no ocurre en el caso del hombre que pretende defraudar, pues su supuesta vivencia de "ser mujer" surge a posteriori para intentar defender su fingida declaración de género.

Por otro lado, la tesis de justificación normal tiene su cumplimiento en la asimetría ya señalada por Davidson y expuesta antes en este mismo apartado. Tanto si se cuentan las razones anatómicas como las experienciales como razones válidas, el cumplimiento de esta tesis debería comenzar por un mejor acceso a estas. En lo relativo a las experiencias y vivencias de las personas, ya ha quedado señalado que desde la primera persona existe un privilegio de interpretación. Esto justifica colocar al testimonio de la propia persona como un modo mejor de conocer su propia identidad que intentar interpretar por uno mismo desde un punto de vista externo (Gertler 2020).

En lo relativo al cuerpo de las personas, la justificación no radica en la capacidad de observación empírica, sino en las limitaciones éticas de invasión de privacidad. Dicho de otro modo, solo la propia persona debe poder decidir a quién comunica o muestra sus genitales u otras consideraciones corporales o biográficas. Por tanto, la determinación de género mediante la genitalidad debería rechazarse y abogar por la autoridad de la primera persona que, en este sentido, estaría justificada por las razones morales señaladas (Bettcher 2009, 107). Así, la tesis de justificación normal estaría satisfecha en la medida en que el testimonio de una persona sobre su propia identidad de género es una mejor forma de crear un juicio al respecto que emplear percepciones y razonamientos en tercera persona.

\section{Conclusiones}

El objetivo fundamental en este artículo se centraba en la validez y justificación de la autodeterminación de la identidad de género, que acaban siendo demostradas mediante las tesis de justificación de la autoridad y el fenómeno de la autoridad de la primera persona.

Para alcanzar esta demostración, los dos primeros apartados sirven para analizar y exponer la forma tradicional en que se determina la identidad de género, tanto a nivel institucional como social. A rasgos generales, la determinación del sexo de los individuos se realiza de forma prácticamente hegemónica basándose en criterios de genitalidad u otras características físicas. No solo en el momento del nacimiento, sino también en el resto de las etapas de la vida. En sentido opuesto, en las últimas décadas se han comenzado a mover vindicaciones relacionadas con el reemplazo por criterios de autodeterminación, que prioricen la vivencia en primera persona del individuo sobre otras características físicas.

Los criterios tradicionales conllevan diversos problemas de conciliación con la despatologización de la transexualidad, con el derecho a la intimidad y con la relevancia de la autoridad de la propia expresión de la identidad. Por el contrario, la autoridad de la primera persona, fenómeno que ha sido extensamente estudiado y desarrollado en epistemología, supone una herramienta que evita estos inconvenientes y que resulta privilegiada para otorgar una justificación apropiada a la visión de la autodeterminación de la identidad de género. Desde esta perspectiva, la identidad de género de una persona puede reconocerse socialmente basándose en el testimonio que el individuo ofrece acerca de su autopercepción. Este testimonio tendría primacía epistémica sobre las interpretaciones que externamente se 
puedan hacer sobre su identidad, de acuerdo con la asimetría del acceso en primera persona a los contenidos mentales propios.

Así, se abre camino a la conexión de la autodeterminación con una teoría de justificación de la autoridad como la de Joseph Raz. Desde la concepción de la autoridad como servicio, se puede ver cómo la autoridad de la primera persona satisface las tesis necesarias para dar una justificación apropiada a la autodeterminación de la identidad de género. Por un lado, se satisface la tesis de dependencia al mostrar cómo las razones ofrecidas por los individuos para rendir cuentas de su identidad son vivencias y autopercepciones que ya existían con anterioridad al momento del testimonio público. Por otro lado, la tesis de justificación normal queda satisfecha también dado que dicho testimonio supone una forma más adecuada de reconocerle a alguien su identidad de género correcta.

De esta forma, la justificación y la validez de la autodeterminación que se buscaban quedan cubiertas y conectadas mediante dicha concepción de la autoridad. La autodeterminación, en virtud de estar basada en la autoridad de la primera persona, se constituye como un modo mejor, más accesible y más confiable de determinar y reconocer la identidad de género de una persona, evitándose los problemas asociados a otros criterios.

\section{Referencias bibliográficas}

Agencia de los Derechos Fundamentales de la Unión Europea (FRA) (2020), A long way to go for LGBTI equality, Luxemburgo: Publications Office of the European Union. Accesible en: https://fra.europa.eu/en/publication/2020/eu-lgbti-survey-results (consultado el 29 de diciembre de 2020).

Alventosa del Río, J. (2016), «Menores transexuales. Su protección jurídica en la Constitución y legislación española», Revista Española de Derecho Constitucional, 107, pp. 153-186.

Bettcher, T. M. (2009), «Trans Identities and First-Person Authority», en: Shrage, L. (ed.): You've Changed: Sex Reassignment and Personal Identity, Nueva York: Oxford University Press, pp. 98-120.

Bettcher, T. M. (2014), «Trapped in the Wrong Theory: Re-Thinking Trans Oppression and Resistance», Signs: Journal of Women in Culture and Society, 39(2), pp. 383-406.

Butler, J. (1986), «Sex and Gender in Simone de Beauvoir's Second Sex», Yale French Studies, 72, pp. 35-49.

Butler, J. (1990), Gender trouble: feminism and the subversion of identity, Londres: Routledge.

Comisión Europea (2020), Union of Equality: LGBTIQ Equality Strategy 2020-2025. Accesible en: https://ec.europa.eu/info/policies/justice-and-fundamental-rights/combatting-discrimination/lesbian-gay-bi-trans-and-intersex-equality/lgbtiq-equality-strategy-2020-2025_en (consultado el 29 de diciembre de 2020).

Comisión Internacional de Juristas (ICJ) (2007), Principios de Yogyakarta: Principios sobre la aplicación de la legislación internacional de derechos humanos en relación con la orientación sexual y la identidad de género. Accesible en: https://www.refworld.org.es/ docid/48244e9f2.html (consultado el 29 de diciembre de 2020).

Davidson, D. (1984), «First Person Authority», Dialectica, 38(2-3), pp. 101-111. 
De Lora, P. (2019), Lo sexual es político (y jurídico), Madrid: Alianza Editorial.

García López, D. (2015), «La intersexualidad en el discurso médico-jurídico», Eunomía. Revista en Cultura de la Legalidad, 8, pp. 54-70.

Gertler, B. (2020), «Self-Knowledge», en: Zalta, E. N. (ed.): The Stanford Encyclopedia of Philosophy. Accesible en: https://plato.stanford.edu/archives/spr2020/entries/selfknowledge/ (consultado el 29 de diciembre de 2020).

Hume, D. (1988), Investigación sobre el entendimiento humano, Jaime de Salas Ortueta (tr.), Madrid: Alianza Editorial.

ILGA World (2020), Trans Legal Mapping Report 2019: Recognition before the Law. Accesible en: https://ilga.org/trans-legal-mapping-report (consultado el 29 de diciembre de 2020).

ILGA-Europe (2020), Annual Review of the Human Rights Situation of Lesbian, Gay, Bisexual, Trans and Intersex People in Europe and Central Asia 2020. Accesible en: https://www.ilga-europe.org/annualreview/2020 (consultado el 29 de diciembre de 2020).

Lawlor, K. (2010), «Elusive Reasons: A Problem for First-Person Authority», Philosophical Psychology, 16(4), pp. 549-564.

Mikkola, M. (2019), «Feminist Perspectives on Sex and Gender», en: Zalta, E. N. (ed.): The Stanford Encyclopedia of Philosophy. Accesible en: https://plato.stanford.edu/archives/ fall2019/entries/feminism-gender/ (consultado el 29 de diciembre de 2020).

Ozturk, B. (2017), «The Negotiative Theory of Gender Identity and the Limits of First-Person Authority», en: Halwani, R., Soble, A., Hoffman, S. y Held, J. (eds.): The Philosophy of Sex, New York: Rowman \& Littlefield, pp. 139-159.

Raz, J. (1975), Practical Reason and Norms, Oxford: Oxford University Press.

Raz, J. (1986), The Morality of Freedom, New York: Oxford University Press.

Schilt, K. y Westbrook, L. (2009), «Doing Gender, Doing Heteronormativity: 'Gender Normals,' Transgender People, and the Social Maintenance of Heterosexuality», Peer Review Articles, 7, pp. 440-464.

Serano, J. (2007), Whipping Girl: A Transsexual Woman on Sexism and the Scapegoating of Feminity, Emeryville: Seal.

Williams, B. (2002), Truth \& Truthfulness: An Essay in Genealogy, Princeton: Princeton University Press.

Wodda, A. y Panfil, V. R. (2015), «Don't Talk to Me about Deception: The Necessary Erosion of the Trans* Panic Defense», Albany Law Review, 78(3), pp. 927-971.

Zagzebski, L. (2012), Epistemic Authority: A Theory of Trust, Authority and Autonomy in Belief, New York: Oxford University Press. 